\title{
Fuzzy super twisting algorithm dual direct torque control of doubly fed induction machine
}

\author{
Boumaraf Farid ${ }^{1}$, Boutabba Tarek ${ }^{2}$, Belkacem Sebti ${ }^{3}$ \\ ${ }^{1}$ Department of Transport Engineering, University of Constantine 1, Algeria \\ ${ }^{2}$ Department of Electrical Engineering, University of Khenchela, Algeria \\ ${ }^{3}$ Department of Electrical Engineering, University of Batna 2, Algeria
}

\begin{tabular}{l} 
Article Info \\
\hline Article history: \\
Received Jul 25, 2020 \\
Revised Mar 13, 2021 \\
Accepted Mar 23, 2021 \\
\hline Keywords: \\
Double direct torque control \\
Fuzzy logic \\
Second-order sliding mode \\
control \\
Super twisting algorithm
\end{tabular}

\begin{abstract}
This paper proposes the fundamental aspects of hybrid nonlinear control which is composed of the super twisting algorithm (STA) based second order sliding mode control applying fuzzy logic method (FSOSMC), with pertinent simulation results for a doubly fed induction machine (DFIM) drive. To minimize chattering effect phenomenon due to Signum function employed in sliding mode algorithm, a new method is proposed. This technique consists in replacing the signum function by fuzzy switching function in the SOSMC to minimize flux and torque ripples. This FSOSMC is associated to the double direct torque control DDTC of the doubly fed induction machine (DFIM) by combining the advantages of fuzzy logic (FL) and the advantages of super-twisting sliding mode. The FSOSMC-DDTC strategy is compared with a PI-DDTC and SOSMC-DDTC. Simulation results demonstrate good efficiency and excellent robustness of the hybrid nonlinear controller.
\end{abstract}

This is an open access article under the CC BY-SA license.

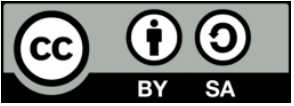

\section{Corresponding Author:}

Boumaraf Farid

Department of Transport Engineering

University of Constantine 1

Constantine, Algeria

Email: farideltb@yahoo.fr

\author{
NOMENCLATURE \\ $V_{s(\alpha, \beta)}, V_{r(\alpha, \beta)} \quad$ Stator, rotor voltage vectors in $\alpha, \beta$ reference \\ $I_{s(\alpha, \beta)}, I_{r(\alpha, \beta)} \quad$ Stator, rotor current vectors in $\alpha, \beta$ reference \\ $\varphi_{s(\alpha, \beta)}, \varphi_{r(\alpha, \beta)} \quad$ Stator, rotor flux linkage vectors in $\alpha, \beta$ reference \\ $\Omega \quad$ Mechanical speed \\ $R_{s}, R_{r} \quad$ Stator and rotor resistances \\ $L_{s}, L_{r} \quad$ Stator and rotor self Inductances \\ $\rho_{s, r} \quad$ Stator and rotor flux angular positions \\ $\sigma \quad$ leakage coefficient \\ $J \quad$ Moment of inertia \\ $\omega_{s}, \omega_{r} \quad$ Stator and rotor pulsations \\ $\mu_{\Omega} \delta_{\Omega} \quad$ Constant positive \\ $\mathrm{T}_{\mathrm{e}} \quad$ Electromagnetic torque
}




\section{INTRODUCTION}

Since the middle of the eighties, the development of the efficiency of induction machines has not been stalled, several previous studies allowed toapplying diverse control technique, and the most common of them, the direct torque control (DTC) [1], [2], because of its many advantages, like fasterdynamic response and less complexity. In [3], Ourici the author proposed to introduce the dual-FOC used inthe rotor and stator of the DFIM simultaneously. Bonnet [4], and Boumaraf [5] use the flux model of DFIM with second switching table in the rotorto improve the DDTC. The DDTC suffers from disadvantages ofvariation in the switching frequency, flux and torque ripples. Recently methods have been proposed to resolve this drawbacks; some papers focus on control optimization of a DFIM [6], some paper focus on low-speed sensorless double DTC for DFIM [7], and other papers propose the introducingof fuzzy logic technique [8], [9], while [10] propose the artificial neural network in DDTC of DFIM. Nevertheless, there are a few difficulties that limit the use of these kinds of controllers, such as a variable switching frequency, torque and flux ripple. In many research papers, these effects are minimized by using space-vector modulation (SVM) method [11], algorithm genetic strategy [12] and feedback linearization [13], but until now, the realization of these algorithms in practice remains more complicated and more expensive than conventional DTC.

Recently, sliding mode control (SMC) was integrated largely in the command of nonlinear systems. [14], [15] have been focused out the remarkable dynamic performances who own SMC in term of improving DTC against the parametric variation. However, this strategy law represents the chattering phenomenon caused by using the sign function. For that, further research is required to eliminate these disadvantages, some authors [16]-[22] proposed the SOSMC, other researchers have been proposed associate the SMC with other techniques like SMC-SVM [23], [24], SMC-feedback control [25], SVM-PID [26] and FL-SMC [27][30]. However, this paper presents the DDTC for DFIM using a novel hybridization between FL and SOSMC technique. The main contributions of this work are:

- The new control technique is introduced by embedding a FL strategy into the SOSMC.

- The switching frequency is limited and also the ripples inthe torque, stator and rotor flux are reduced.

- The performance of the DFIM controlled by FSOSMC is comparedto that of the DFIM controlled by PI and SOSMC so as to prove the improvements made.

The rest paper part is structured is being as: The DFIM model is described in section 2. Section 3 gives a basic idea of the DDTC. In section 4, the STAisexplained, while theFSOSMC is discussed in section 5. Section 6 presents the simulation results using the MATLAB/Simulink. Finally, conclusion is drawn in section 7 .

\section{MATHEMATICAL MODEL OF DFIM}

The traditional model of DFIM in the laboratory frame $(\alpha, \beta)$ is written is being as in (1) [6]. The parameters of DFIM shows in the appendix.

$$
\left\{\begin{array} { l } 
{ V _ { s \alpha } = R _ { s } I _ { s \alpha } + \frac { d } { d t } \varphi _ { s \alpha } } \\
{ V _ { s \beta } = R _ { s } I _ { s \beta } + \frac { d } { d t } \varphi _ { s \beta } } \\
{ V _ { r \alpha } = R _ { r } I _ { r \alpha } + \frac { d } { d t } \varphi _ { r \alpha } + \omega _ { r } \varphi _ { r \beta } } \\
{ V _ { r \beta } = R _ { r } I _ { r \beta } + \frac { d } { d t } \varphi _ { r \beta } - \omega _ { r } \varphi _ { r \alpha } }
\end{array} \quad \left\{\begin{array}{l}
\varphi_{s \alpha}=L_{s} I_{s \alpha}+\mu I_{r \alpha} \\
\varphi_{s \beta}=L_{s} I_{s \beta}+\mu I_{r \beta} \\
\varphi_{r \alpha}=L_{r} I_{r \alpha}+\mu I_{s \alpha} \\
\varphi_{r \beta}=L_{r} I_{r \beta}+\mu I_{s \beta}
\end{array}\right.\right.
$$

The expression of electromagnetic torque for the DFIM is defined as in (2) [7]:

$$
\left\|\vec{T}_{e}\right\|=K\left\|\vec{\varphi}_{s}\right\| \cdot\left\|\vec{\varphi}_{r}\right\| \sin (\gamma)
$$

\section{DDTC STRATEGY}

The DDTC strategy involves the separate control of $\vec{\varphi}_{s}$ and $\vec{\varphi}_{r}$ through the selection of optimums inverters switching modes. To decrease or increase the flux amplitudes $\varphi_{s, r}$ and the angular position $\rho_{s, r}$ in each sector, two adjacent voltage vectors can be used. The voltage vectors control of $\varphi_{s, r}$ planes are shown in Figure $1[6]$. 


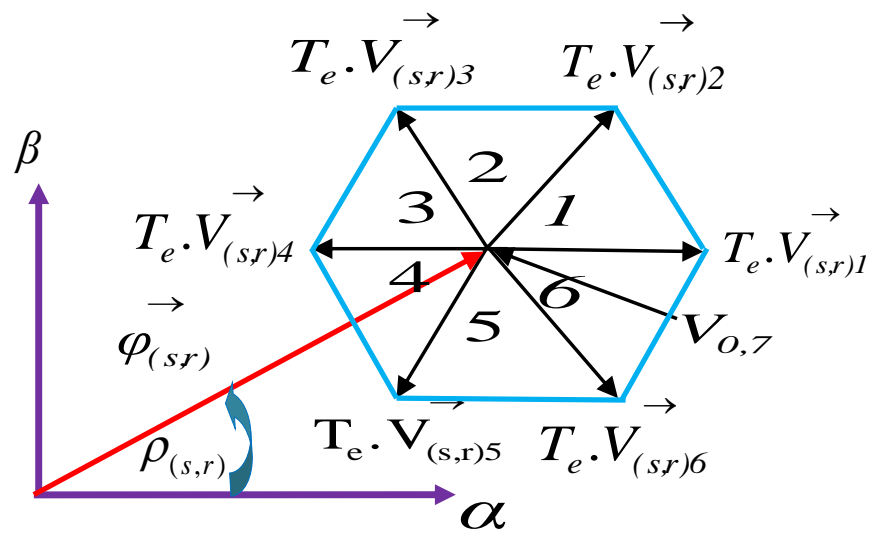

Figure 1. $\overrightarrow{\varphi_{s, r}}$ control in six angular sectors

\section{SUPER-TWISTING DUAL DIRECT CONTROL OF DFIM}

The STA is an exceptional case of SOSMC, where this method is specially developed to control the non linear systems with relative degree 1, respecting the sliding surface [17]. Two parts compose the STA; a discontinuous and continuous part. The sliding surface is defined [18]:

$$
\begin{aligned}
& s_{\Omega}=\Omega_{r e f}-\Omega \\
& \frac{d \Omega}{d t}=\frac{T_{e}-T_{r}-f \Omega}{\mathrm{J}}
\end{aligned}
$$

By replacing (4) into (3) we obtain:

$$
\dot{S_{\Omega}}=\dot{\Omega}_{r e f}-\frac{1}{J}\left(T_{e}-f \Omega-T_{r}\right)
$$

Wedefine:

$$
A_{\Omega}=\dot{\Omega}_{r e f}-\frac{1}{J}\left(f \Omega-T_{r}\right)
$$

Then the (5) became:

$$
\ddot{S}_{\Omega}=\dot{A}-\frac{1}{J} \dot{T}_{e}
$$

The SOSMC contain two parts [18]:

$U=U_{1}+U_{2}$

$\dot{U}_{1}=\left\{\begin{array}{l}-U \quad \text { if }|U| \succ U_{M} \\ -\delta_{\Omega} \operatorname{sign}\left(S_{\Omega}\right) \text { if not }\end{array}\right.$

$\dot{U}_{2}=\left\{\begin{array}{c}-\mu_{\Omega}\left|S_{\Omega}\right|^{1 / 2} \operatorname{sign}\left(\mathrm{S}_{\Omega}\right) \text { if }|\mathrm{U}| \succ \mathrm{S}_{\Omega} \\ -\delta_{\Omega}\left|S_{\Omega}\right|^{1 / 2} \operatorname{sign}\left(S_{\Omega}\right) \text { if not }\end{array}\right.$

if $S_{0}=\infty$ we can simplify the algorithm [23]: 


$$
\left\{\begin{array}{l}
u=-\mu_{\Omega}\left|s_{\Omega}\right|^{1 / 2} \operatorname{sign}\left(s_{\Omega}\right)+u_{1} \\
\dot{u_{1}}=-\delta_{\Omega} \operatorname{sign}\left(s_{\Omega}\right)
\end{array}\right.
$$

The closed loop diagram of STA is presented in Figure 2 [18].

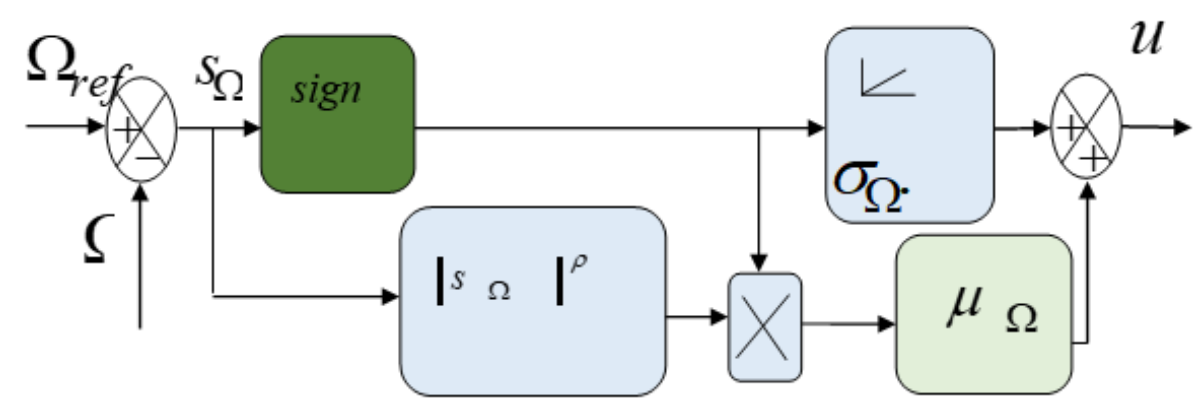

Figure 2. SMC diagram

\section{RELATED WORK}

\subsection{Fuzzy logic-SOSMC}

The FSOSMC have been adopted to solve the problem of chattering, where the sign function has been replaced by an inference fuzzy system. The shapes of all membership functions are defined in Figure 3 . In FSOSMC, in (11) becomes (12):

$$
\left\{\begin{array}{l}
u=-\mu_{\Omega}\left|s_{\Omega}\right|^{1 / 2} \operatorname{fuzzy}\left(s_{\Omega}\right)+\mathrm{u}_{1} \\
\dot{u_{1}}=-\delta_{\Omega} \operatorname{fuzzy}\left(s_{\Omega}\right)
\end{array}\right.
$$

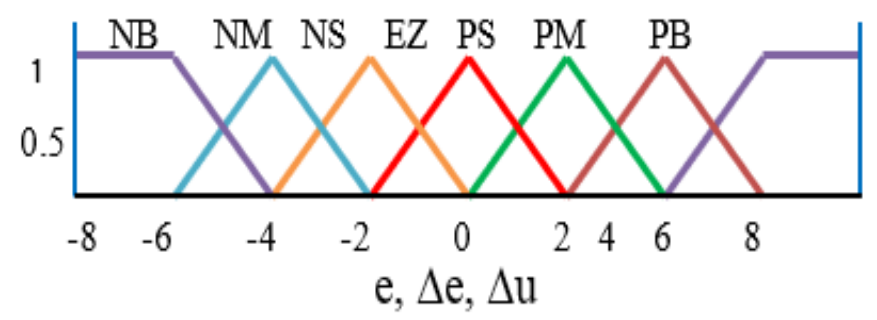

Figure 3. Membership functions (e, $\Delta \mathrm{e}, \Delta \mathrm{u})$

\subsection{Stability analysis}

The analysis and the proof of stability will be exposed to guarantee the system stability. The Lyapuno derivative candidacy is defined by (13):

$$
S_{\Omega} \cdot \dot{S}_{\Omega} \prec 0
$$

We replace this in (5) we get:

$$
\dot{S}_{\Omega}=-\frac{1}{j}\left(\mu_{\Omega}\left|S_{\Omega}\right|^{\frac{1}{2}} \operatorname{sign}\left(S_{\Omega}\right)+\int \sigma_{\Omega} \operatorname{sign}\left(S_{\Omega}\right) d t\right.
$$

And the stability condition according to Lyapunov will be [18]: 
$\Rightarrow S_{\Omega} \cdot \dot{S_{\Omega}}=-\frac{\mu_{\Omega}}{j}\left|S_{\Omega}\right|^{\frac{3}{2}} \operatorname{sign}\left(S_{\Omega}\right)-S_{\Omega} \frac{\sigma_{\Omega}}{j} \int \operatorname{sign}\left(S_{\Omega}\right) d t$

The Lyapunov condition $S_{\Omega} \cdot \dot{S}_{\Omega}<0$ is assured only with coefficients $\left(\mu_{\Omega}, \delta_{\Omega}\right)$ positives.

\section{SIMULATION}

We have simulated the proposed FSOSMC on the MATLAB/Simulink as shown in Figure 4, where the FSOSMC consists in replacing the classical regulator PI by the FSOSMC controller, and a series of tests were done to prove the effaiciency of this new technique of control. Therefore, a comparative results between FSOSMC-DDTC and both PI-DDTC and SOSMC-DDTC techniques have been presented.

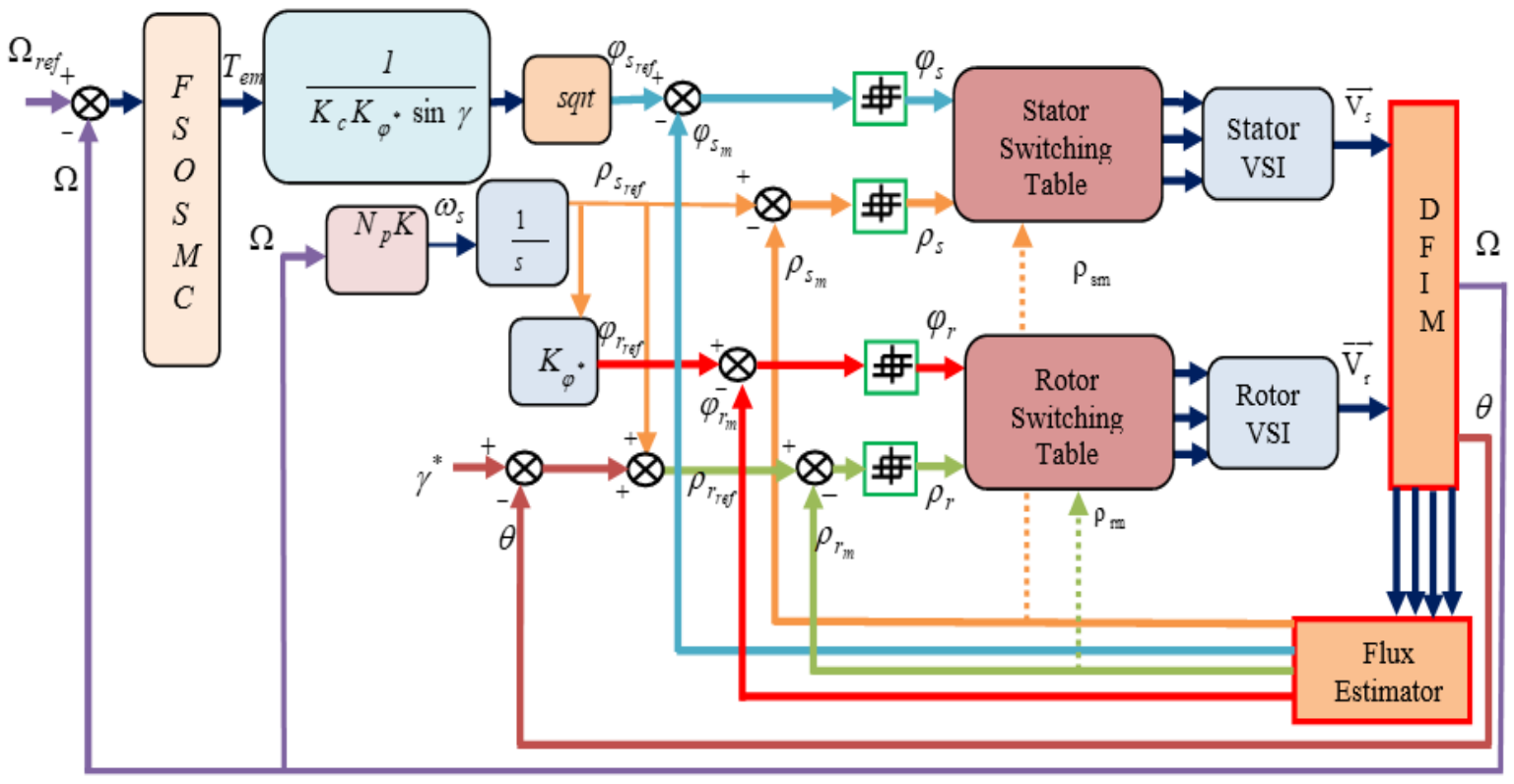

Figure 4. Block diagram of FSOSMC-DDTC scheme for DFIM

\subsection{First test (speed reversal)}

This test consists on varying the speed reference cycle startingfrom the zero value to $180 \mathrm{rad} / \mathrm{s}$, and changingaccording to the time variation to $\mathrm{t}=\left[\begin{array}{llll}1 & 2 & 3 & 4\end{array}\right] \mathrm{s}$ with respectively $\Omega_{r e f}=\left[\begin{array}{lllll}-180 & 50 & -50 & 157\end{array}\right]$. Also, anintroduction of load torque at $\mathrm{t}=2.5 \mathrm{~s}$ value to $25 \mathrm{Nm}$ is presented. The comparative curves between PI, SOSMC and our approach are presented in Figures 5 and 6. It can be noticed that the speed variation cycle produces an important effect on electromagnetic torque, rotor and stator flux curves. While the use of the FSOSMC controller give a good performance: Allows the speed to judiciously follow its different reference values with better transient response time. The improvement of the FSOSMC in terms of overshoot, settling time, this result is indicated in Table 1, the rejects of the load disturbance is very rapid with a negligible steady state error, and FSOSMC minimize the chattering effect in the flux and torque ripple compared to the results obtained in [6]-[10].

\subsection{Second test (variation of the load torque)}

The imposed profile of the load torque changes from $0 \mathrm{Nm}$ value to $25 \mathrm{Nm}$, this variation is done respectively is being as for a time value $\mathrm{t}=\left[\begin{array}{lll}1 & 2 & 3\end{array}\right] \mathrm{s}$ and a torque value $\boldsymbol{T}_{e}=\left[\begin{array}{lllll}10 & 25 & 30 & 15\end{array}\right] \mathrm{Nm}$. Figures 7 and 8 show that the FSOSMC control law is robust to the variations and the presence of disturbances. Moreover the results obtained in Figure 5, Figures 7, 8, 9 and 10 show that the toque has less ripple of $2 \mathrm{Nm}$ and 1.3 N.m compared to PI, SOSMC, and to the results obtained in [8]-[10]. The rotor and stator flux ripples are also considerably reduced. 

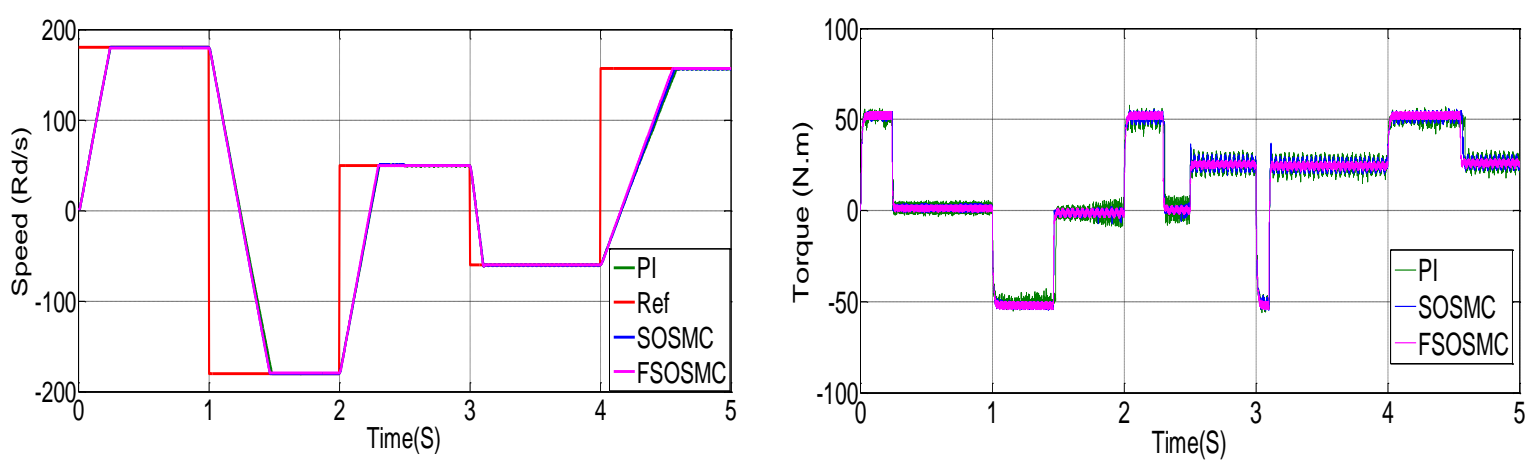

Figure 5. FSOSMC, SOSMC and PI strategy responses (under speed variation)
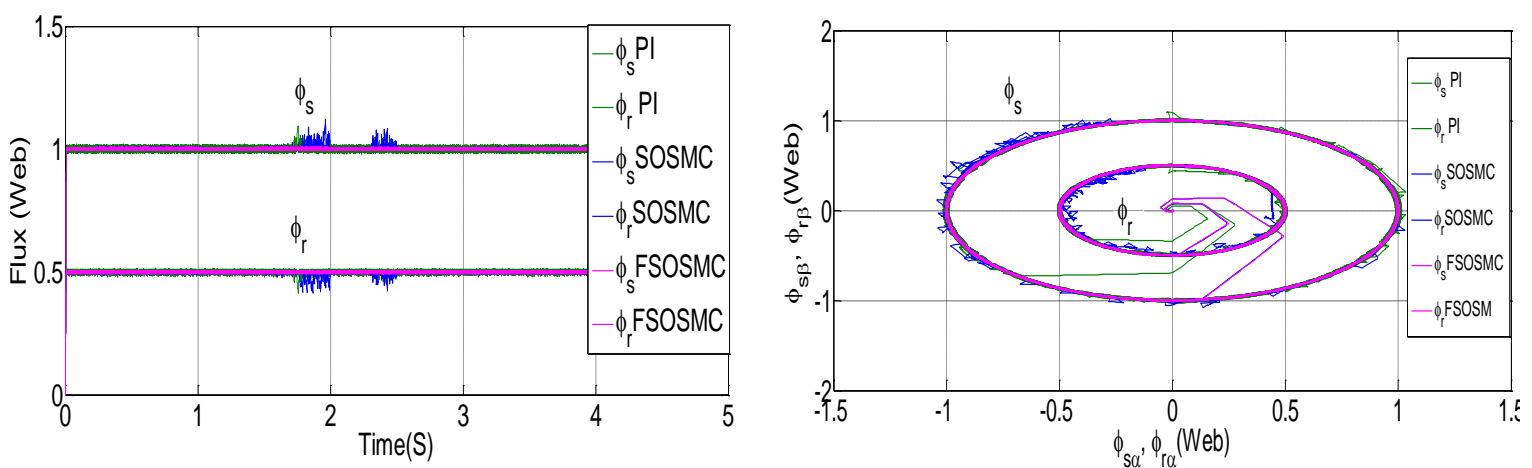

Figure 6. FSOSMC, SOSMC and PI strategy responses (under speed variation)
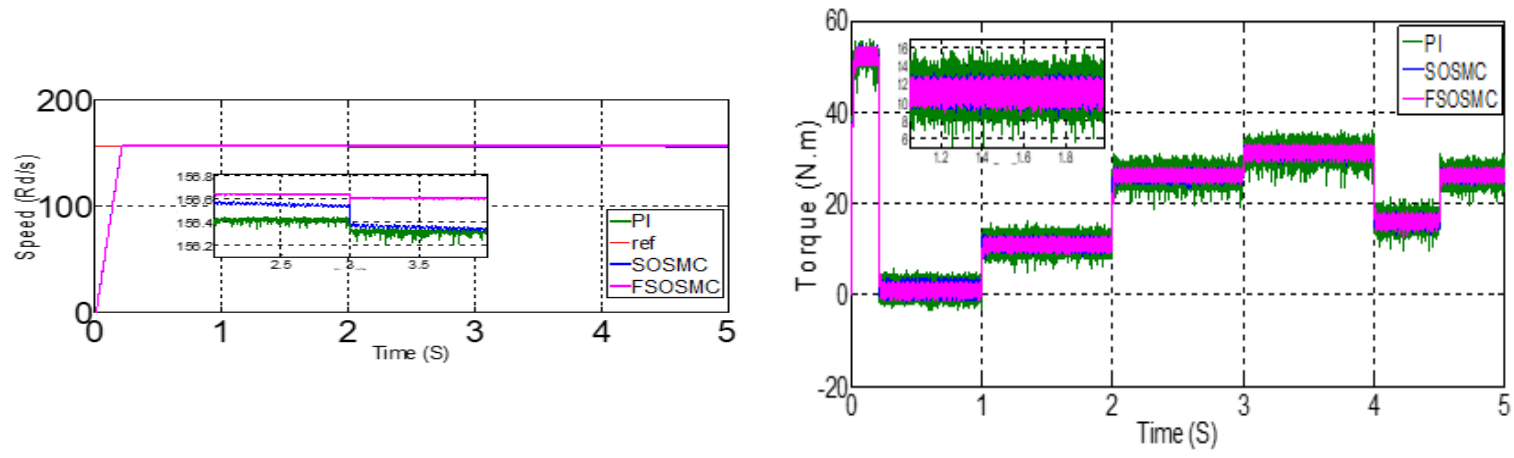

Figure 7. FSOSMC, SOSMC and PI strategy responses (under load torque variation)
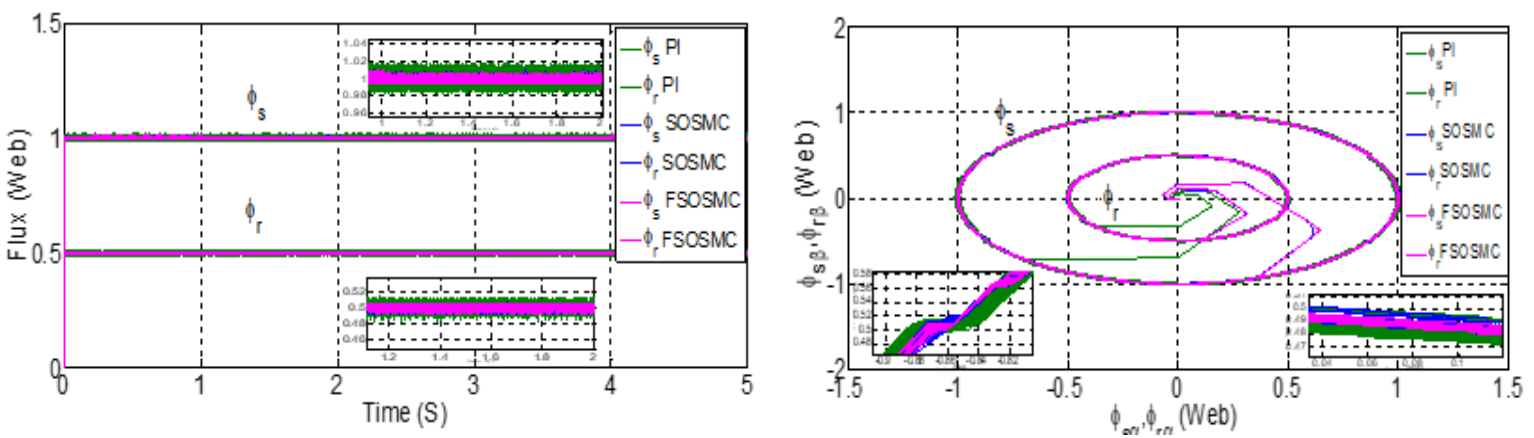

Figure 8. FSOSMC, SOSMC and PI strategy responses (under load torque variation) 


\subsection{Third test (robustness test)}

For testing the performances of the new FSOSMC in our strategy, $R_{r}, R_{s}$ have been reduced to $50 \%$ of their real valuesinthe intervals of time $\mathrm{t}=1 \mathrm{~s}$ to $\mathrm{t}=1.5 \mathrm{~s}$ and from $\mathrm{t}=2.9 \mathrm{~s}$ to $\mathrm{t}=3.5 \mathrm{~s}$ respectively, then we increased their value to the double at time fixedto $\mathrm{t}=2 \mathrm{~s}$ to $2.5 \mathrm{~s}$ for the stator resistance, and between 3.9 and $4.5 \mathrm{~s}$ for the rotor resistance as shown in Figure 9. Figures 10 and 11 shows a comparison between different techniques of control under parametric variation. We observe the effect of these variations on the torque and also on both stator and rotor flux. This comparison proves clearly that the performance of the proposed algorithm under parametric variations is better than both the PI and SOSMC controller. Table 1 summarizes the comparison between different techniques.

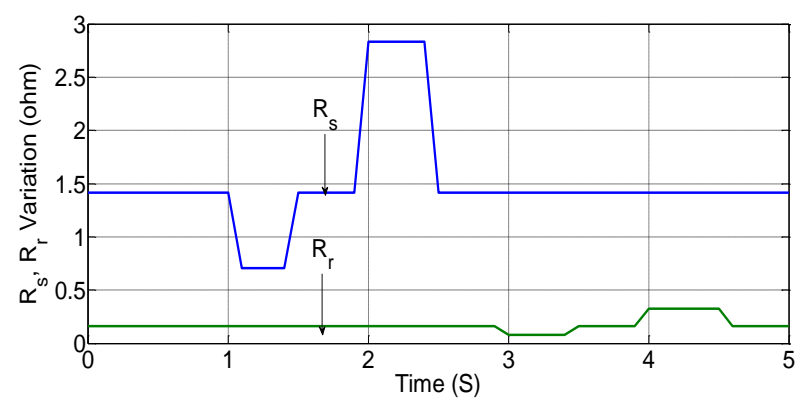

Figure 9. $R_{s}$ and $R_{r}$ resistance variations
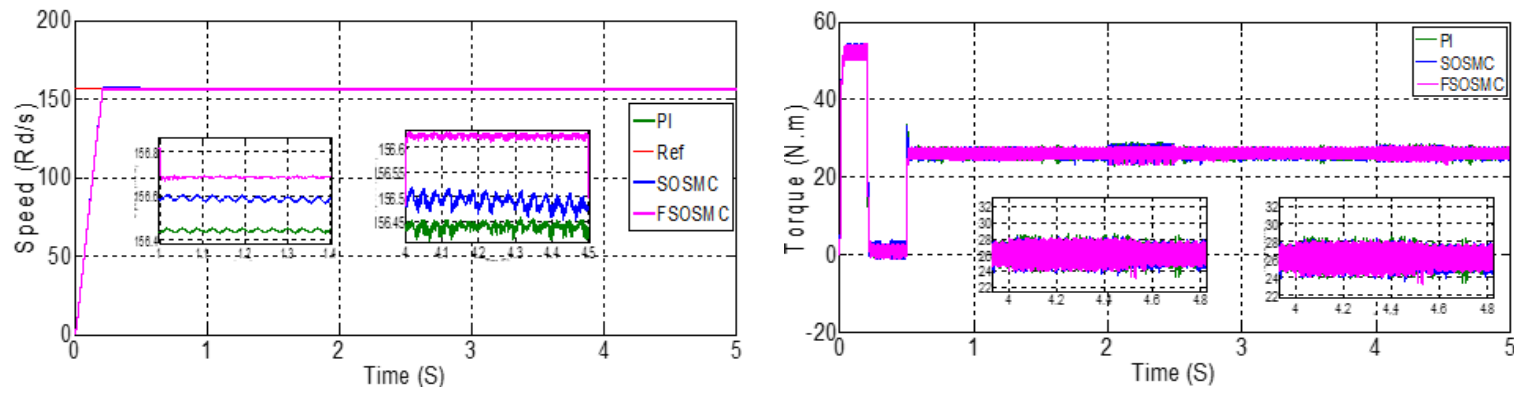

Figure 10. FSOSMC, SOSMC and PI strategy responses (under parameter variations)
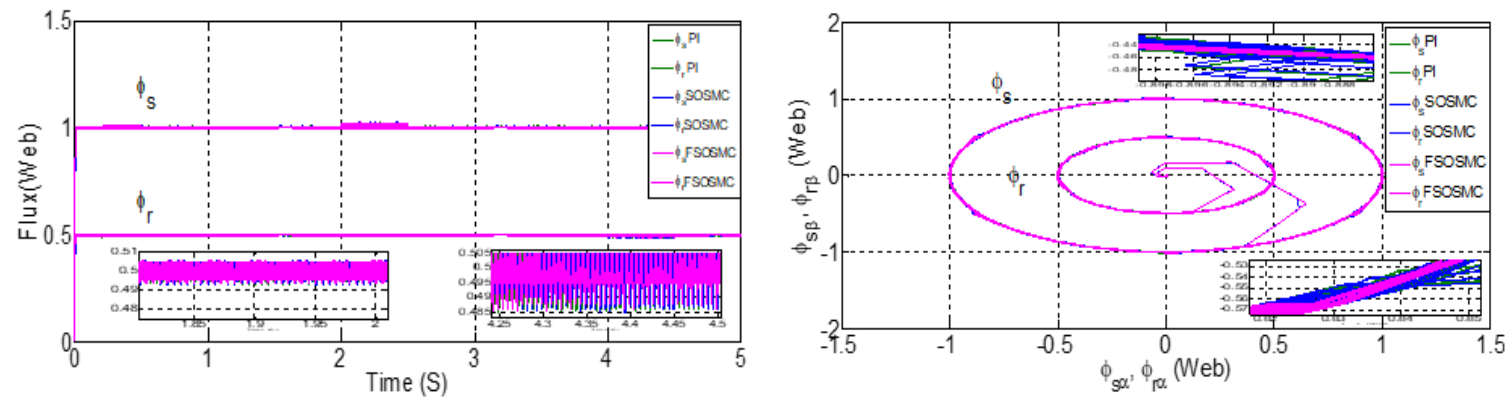

Figure 11. FSOSMC, SOSMC and PI strategy responses (under parameter variations)

Table 1. Performances comparison of the three approachs

\begin{tabular}{cccccc}
\hline Approach & PI-DDTC & $\begin{array}{c}\text { SOSMC- } \\
\text { DDTC }\end{array}$ & $\begin{array}{c}\text { FSOSMC- } \\
\text { DDTC }\end{array}$ & $\begin{array}{c}\text { Improvement compared } \\
\text { to PI }(\%)\end{array}$ & $\begin{array}{c}\text { Improvement compared } \\
\text { to SOSMC }(\%)\end{array}$ \\
\hline Torqueripple $(\mathrm{N} . \mathrm{m})$ & 4.5 & 3.8 & 2.5 & 44.44 & 34.21 \\
Stator flux ripple $(\mathrm{Wb})$ & 1.02 & 0.5 & 0.3 & 70.58 & 40 \\
Rotor flux ripple $(\mathrm{Wb})$ & 0.48 & 0.35 & 0.25 & 47.92 & 28.57 \\
Rising time of the speed & 0.218 & 0.215 & 0.213 & 2.3 & 0.9 \\
\hline
\end{tabular}




\section{CONCLUSION}

In this paper, FSOSMC-DDTC for DFIM has been presented to improve the DDTC of DFIM performance. The suggested control has been compared to the PI-DDTC and SOSMC-DDTC. The simulation results demonstrate that the DDTC using FSOSMC worked well especially with regard to torque and flux ripples minimization, less performance degradation due to machine parameter variations, robustness to load changes andsystem disturbances, which demonstrate the feasibility of the FSOSMC method. The superiority of the suggested FSOSMC-DDTC isemphasized by the following points: (1) FSOSMC is developed to efficiently control a DFIM. Compared with existing control techniques such as previous studies, the rate of effectiveness presents interesting attributes, such as, high tracking performances and low chattering; (2) The practical realization of the suggested methods will wish be conducted in the future.

\section{APPENDIX}

\begin{tabular}{|c|c|}
\hline \multicolumn{2}{|c|}{ A. DFIM parameters } \\
\hline Symbol & Value \\
\hline$P_{n}$ & $4 \mathrm{KW}$ \\
\hline$L_{s}$ & $0.163 \mathrm{H}$ \\
\hline$L_{r}$ & $0.021 \mathrm{H}$ \\
\hline$R_{s}$ & $1.417 \Omega$ \\
\hline$R_{r}$ & $0.163 \Omega$ \\
\hline$\mu$ & $0.055 \mathrm{H}$ \\
\hline$P$ & 2 \\
\hline$J$ & $0.066 \mathrm{Kg} \mathrm{m} 2$ \\
\hline
\end{tabular}

\section{REFERENCE}

[1] J. H. Ryu, K. W. Lee, and J. S. Lee, "A unified flux and torque control method for DTC-based induction-motor drives," in IEEE Transactions on Power Electronics, vol. 21, no. 1, pp. 234-242, Jan. 2006, doi: 10.1109/TPEL.2005.861176.

[2] A. Zemmit and S. Messalti, "Modeling and Simulation of Doubly Fed Induction Motor (DFIM) Control using DTC and DFOC: a comparative study," International Journal of Electrical and Computer Engineering (IJECE), vol. 8, no. 11 , pp. 5623-5628, 2016, doi: 10.11591/ijece.v9i2.pp761-770.

[3] A. Ourici, "Double flux orientation control for a doubly fed induction machine," Electrical Power and Energy Systems, vol. 43, no. 1, pp. 617-620, 2012, doi: 10.1016/j.ijepes.2012.05.071.

[4] F. Bonnet Francois, P. Vidal, and M. Pietrzak-David, "Dual Direct Torque Control of Doubly Fed Induction Machine," in IEEE Transactions on Industrial Electronics, vol. 54, no. 5, pp. 2482-2490, Oct. 2007, doi: 10.1109/TIE.2007.900330.

[5] F. Boumaraf, M. L. Bendaas, R. Abdessemed, and S. Belkacem, "Direct torque control of doubly fed induction machine," International Journal on Electrical Engineering and Informatics, vol. 7, no. 3, pp. 541-555, Sep. 2015.

[6] F. Bonnet and M. Pietrzak-David, "Control optimization of a Doubly Fed Induction Machine," 2008 IEEE Power Electronics Specialists Conference, Rhodes, Greece, 2008, pp. 2579-2585, doi: 10.1109/PESC.2008.4592329.

[7] M. Abdellatif, M. Debbou, I. Slama-Belkhodja, and M. Pietrzak-David, "Simple Low-Speed Sensorless Dual DTC for Double Fed Induction Machine Drive," in IEEE Transactions on Industrial Electronics, vol. 61, no. 8, pp. 3915-3922, Aug. 2014, doi: 10.1109/TIE.2013.2288190.

[8] N. El Ouanjli, S. Motahhir, A. Derouich, A. El-Ghzizal, A. Chebabhi, and M. Taoussi, "Improved DTC strategy of doubly fed induction motor using fuzzy logic controller," Energy Reports, vol 5, pp. 271-279, 2019, doi: 10.1016/j.egyr.2019.02.001.

[9] M. Uddin and M. Hafeez, "FLC-Based DTC Scheme to Improve the Dynamic Performance of an IM Drive," in IEEE Transactions on Industry Applications, vol. 48, no. 2, pp. 823-831, 2012, doi: 10.1109/TIA.2011.2181287.

[10] S. Khadar and A. Kouzou, "Dual Direct Torque Control of Doubly Fed Induction Machine using Artificial Neural Network," 2018 3rd International Conference on Pattern Analysis and Intelligent Systems (PAIS), Tebessa, 2018, pp. 1-7, doi: 10.1109/PAIS.2018.8598497.

[11] M V. Kazemi, A S. Yazdankhah, and H M. Kojabadi," Direct power control of DFIG based on discrete space vector modulation," Renewable Energy, vol. 35, no. 5, pp. 1033-1042, 2010, doi: 10.1016/j.renene.2009.09.008.

[12] A. Zemmit, S. Messalti, and A. Harragab, "A new improved DTC of doubly fed induction machine using GA-based PI controller," Ain Shams Engineering Journal, vo. 9, no. 4, pp. 1877-1885, 2018, doi: 10.1016/j.asej.2016.10.011.

[13] Y. Choi, H. H. Choi, and J. Jung, "Feedback Linearization Direct Torque Control With Reduced Torque and Flux Ripples for IPMSM Drives," in IEEE Transactions on Power Electronics, vol. 31, no. 5, pp. 3728-3737, May 2016, doi: 10.1109/TPEL.2015.2460249.

[14] J. Hu, H. Nian, B. Hu, Y. He and Z. Q. Zhu, "Direct Active and Reactive Power Regulation of DFIG Using SlidingMode Control Approach," in IEEE Transactions on Energy Conversion, vol. 25, no. 4, pp. 1028-1039, Dec. 2010, doi: 10.1109/TEC.2010.2048754.

Fuzzy super twisting algorithm dual direct torque control of doubly fed induction machine (Boumaraf Farid) 
[15] M. S. Carmeli and M. Mauri, "Direct torque control as variable structure control: Existence conditions verification and analysis," Electric Power Systems Research, vol. 81, no. 6, pp. 1188-1196, 2011, doi: 10.1016/j.epsr.2011.01.007.

[16] I. Matraji, A. Al-Durra, and R. Errouissi, "Design and experimental validation of enhanced adaptive second-order SMC for PMSG-based wind energy conversion system," Electrical Power and Energy Systems, vol. 103, pp. 21-30, 2018, doi: 10.1016/j.ijepes.2018.05.022.

[17] Z. Boudjema, R. Taleb, Y. Djeriri, and A. Yahdou, "A novel direct torque control using second order continuous sliding mode of adoubly fed induction generator for a wind energy conversion system," Turkish Journal of Electrical Engineering \& Computer Sciences, vol. 25, no. 2, pp. 965-975, 2017, doi: 10.3906/elk-1510-89.

[18] A. Listwan, "Application of Super-Twisting Sliding Mode Controllers in Direct Field-Oriented Control System of Six-Phase Induction Motor," Experimental Studies, Power Electronics and Drives, vol. 3, no. 1, pp. 23-34, 2018.

[19] L. Laggoun, L. Youb, S. Belkacem, S. benaggoune, and A. Craciunescu, "Direct torque control using second order sliding mode of a double star permanent magnet synchronous machine," University Politehnica of Bucharest Scientific Bulletin Series C Electrical Engineering and Computer Science, vol. 80, no. 4, pp. 93-106, 2018.

[20] M. Nasiri, S. Mobayen, and Q. M. Zhu, "Super-Twisting Sliding Mode Control for Gearless PMSG-Based Wind Turbine," Hindawi Complexity Journal, vol. 1, Apr. 2019, doi: 10.1155/2019/6141607.

[21] C. Lascu and F. Blaabjerg, "Super-twisting sliding mode direct torque contol of induction machine drives," 2014 IEEE Energy Conversion Congress and Exposition (ECCE), Pittsburgh, PA, USA, 2014, pp. 5116-5122, doi: 10.1109/ECCE.2014.6954103.

[22] A. Levant and L. Alelishvili, "Integral High-Order Sliding Modes," in IEEE Transactions on Automatic Control, vol. 52, no. 7, pp. 1278-1282, Jul. 2007, doi: 10.1109/TAC.2007.900830.

[23] I. Yaichi, A. Semmah, P. Wira, and Y. Djeriri, "Super-twisting Sliding Mode Control of a Doubly-fed Induction Generator Based on the SVM Strategy," Periodica Polytechnica Electrical Engineering and Computer Science, vol. 63, no. 3, pp. 178-190, 2019, doi: 10.3311/PPee.13726.

[24] F. Mazouz, S. Belkacem, I. Colak and S. Drid, "Direct Power Control of DFIG by Sliding Mode Control and Space Vector Modulation," 2018 7th International Conference on Systems and Control (ICSC), Valencia, 2018, pp. 462-467, doi: 10.1109/ICoSC.2018.8587848.

[25] A. Levant, "Higher-order sliding modes, differentiation and output feedback control," International Journal of Control, vol. 76, no. 9-10, pp. 924-941, 2003, doi: 10.1080/0020717031000099029.

[26] K. S. Holkar and L. M. Waghmare, "Sliding Mode Control with Predictive PID Sliding Surface for Improved Performance," International Journal of Computer Applications, vol. 78, no. 4, pp. 0975-8887, September 2013.

[27] N. Bounar, S. Labdai, and A. Boulkroune, "PSO-GSA based fuzzy sliding mode controller for DFIG-based wind turbine," ISA Transactions, vol. 85, pp. 177-188, 2019, doi: 10.1016/j.isatra.2018.10.020.

[28] Sid. A. El. M. Ardjoun, M. Abid, A. Aissaoui, and A. Naceri, "A robust fuzzy sliding mode control applied to the double fed induction machine," International journal of circuits, systems and signal processing, vol. 5, no. 4, pp. 315-21, 2011.

[29] Sid. A. El. M. Ardjoun and M. Abid, "Fuzzy sliding mode control applied to a doubly fed induction generator for wind turbines," Turkish Journal of Electrical Engineering \& Computer Sciences, vol. 23, pp. 1673-1686, 2015, doi: 10.3906/elk-1404-64.

[30] A. Saghafinia, H. W. Ping, M. N. Uddin and K. S. Gaeid, "Adaptive Fuzzy Sliding-Mode Control Into ChatteringFree IM Drive," in IEEE Transactions on Industry Applications, vol. 51, no. 1, pp. 692-701, Jan.-Feb. 2015, doi: 10.1109/TIA.2014.2328711. 